\title{
PUBLICATION PRODUCTIVITY AND PROFESSIONAL POSITION: CROSS-NATIONAL EVIDENCE ON THE ROLE OF ORGANIZATIONS
}

\author{
K. D. KNORR, ${ }^{*}$ R. MITTERMEIR** \\ *Department of Sociology, University of Pennsylvania (USA) \\ "*Department of Computer Sciences, University of Texas, Austin (USA)
}

\begin{abstract}
Studies of stratification in science have increasingly accepted the idea that science is a highly stratified and elitist system with skewed distributions of productivity and rewards. Attempts to explain the higher productivity of higher status scientists by pointing to their greater ease of publication as far as acceptance of their work by journals and publishers is concerned were not supported by the data in some recent studies. If status in general does not confer greater ease of publication the present paper argues that position within a research organization does confer greater ease of author - or co-authorship - and this is the major explanatory variable accounting for productivity differences within research laboratories as far as quantity of articles (and books) is concerned. Upward moves in a laboratory's formal or informal position hierarchy are associated with a change of a scientist's research involvement from goal executing to goal setting functions as well as with an increasing access to scientific manpower and project money. Goal setting tasks provide for a significant reduction of time-expenditures in research necessary to assure that the scientist is identified with the research results; consequently, they allow for an involvement in more research tasks than originally. Equivalently, resources in scientific manpower and project money act as a multiplying element as far as quantity of output is concerned.
\end{abstract}

\section{Productivity and stratification in science}

Studies of stratification in science have long accepted the idea that science is a highly stratified and elitist system with skewed distributions of productivity and rewards (e.g. Lotka, ${ }^{1}$ Price, ${ }^{2}$ Merton $^{3}$ ). There have been studies of productivity and stratification on scientists of a variety of disciplines, including physiologists (Meltzer et al. ${ }^{4,5}$ ), psychologists (Clark ${ }^{6}$ ), sociologists (Meltzer, ${ }^{7}$ Axelson, ${ }^{8}$ Babchuk and Bates, ${ }^{9}$ Clemente. ${ }^{10}$ Knorr et al. ${ }^{11}$ ), medical researchers (Ben David ${ }^{12}$ ), biologists and political scientists (Crane ${ }^{13}$ ), psychometricians (Thomasson and 
Stanley ${ }^{14}$ ), physicists (Cole and Cole, ${ }^{15}$ Gaston, ${ }^{16}$ Cole, ${ }^{17}$ Zuckerman and Merton $^{18}$ ) and chemists (Hagstrom, ${ }^{19}$ Blume and Sinclair ${ }^{20,21}$ ). Other studies, like those of Pelz and Andrews, ${ }^{22}$ Hargens and Hagstrom, ${ }^{23}$ Hargens, ${ }^{24,25}$ Allison and Stewart, ${ }^{26}$ Mittermeir and Knorr $^{27}$ or the studies collected in Andrews ${ }^{28}$ cover a variety of scientists from different specialties and disciplines.

Many of the earlier studies which use citation counts as well as the results of Crane $^{13}$ seemingly suggests that rewards received in science might not result from an individual's general contribution to science but must be linked to the preferential citing of the eminent or to the appointment of eminent rather than productive scientists (see also Cole et al. $^{29}$ ). However, Zuckerman and Merton ${ }^{18}$ found that the formal control mechanisms of science such as reviewing and publication processes are not affected by status differentials of the authors of papers submitted. Findings such as those by Hargens and Hagstrom ${ }^{23}$ and Hagstrom ${ }^{19}$ support these conclusions: Hargens and Hagstrom showed that status does not affect productivity on the individual level, although it does on the aggregate.

If the large differences in scientists' performance cannot simply be explained away as the "unmerited" consequence of status differentials (cf. Ref. ${ }^{20}$ p. 134), they may well make sense within the more complex sociological explanation of "accumulative advantage" (cf. Cole and Cole ${ }^{30}$ ). In essence this hypothesis says that productive scientists are likely to be even more productive in the future because of a variety of social mechanisms, while those who are unproductive are likely to decline further in their productivity. According to Cole and Cole, an alternative interpretation generally found in the literature is the "sacred spark" hypothesis which associates productivity differences with predetermined differences in scientists' motivation and capabilities. While the accumulative advantage hypothesis equally draws upon the mechanism of motivation, the latter is seen to be stimulated and reinforced by recognition and the expectation of repeated and exceeding achievements rather than being linked to a scientists' given, psychological make-up. More important, the accumulative advantage hypothesis points to mechanisms such as access to resources (time, money, manpower, intormation or a stimulating environment) which accrue to those who are recognized and facilitate their research and productivity. Thus if status does not confer greater ease of publication in the simple sense of biasing reviewers and publishing companies toward a more ready acceptance of the work of high status scientists, it may well confer greater ease of production through intervening means and channels not accessible to those in low positions. To be sure, these intervening variables will have to be established more concretely in order to rule out the equally possible interpretation that differences in publication productivity can solely be explained by differential ease of authorship, that is by norms which assure supervisory scientists to be men- 
tioned as author or co-author of a paper independent of their actual involvement in the research work (see Zuckerman ${ }^{31}$ ). ${ }^{\mathbf{a}}$

In the present paper, we attempt to identify some of these variables and to enhance the thesis of a greater ease of production linked to professional status by comparing scientists in different types of organizations across a variety of disciplines with respect to what explains their productivity differences. Specifically, it is shown that variables linked to the structure of work organization connected with a scientist's position within a research unit account to a significant degree for the performance differénces encountered. As argued by Whitley in a series of papers, ${ }^{\mathbf{2 - 3 4}}$ scientists may be affected much more by organizational settings and structures than usually assumed in stratification studies. While the search for scientific communities came to be considered as one of the key tasks of sociology of science per se, "science as a form of work occuring in employing organizations has been almost entirely ignored in sociological studies of the sciences" (Ref. ${ }^{32}$ p. 3). In the light of such criticism, we must stress that the present study owes more to the tradition of organizational sociology and its occasional explorations of scientists in organizations (e.g. Pelz and Andrews ${ }^{22}$ ) than to sociology of science. However, this heritage can at the same time be seen as one of the limitations of the data presented, since the intellectual or cognitive organization of research emphasized in new developments of sociology of science (e.g. Whitley, ${ }^{3,38}$. Weingart, ${ }^{39}$ ) has been taken into account only to the degree to which types of scientific disciplines and organizational context can be taken to approximate cognitive content.

Thus, the claims to be made here are modest ones: the study purports to identify a small set of variables having to do with the organization of research work as usually ignored in sociology of science which apparently account for a significant amount of variance in scientists' publication productivity within different types of discipline and organizational context; to specify the interrelationship between these variables with the help of structural equation models; and to show that the data presented do not support the sacred spark hypothesis while being consistent with the idea of accumulative advantage. In order to establish these claims we will first examine the relationship between age as a proxy for the position a scientist has attained in a research organization and his or her publication productivity. We will

\footnotetext{
"As an example of such norms, let us refer to the principle of "noblesse oblige" which Zuckerman observes in the name-ordering of authors (Ref. ${ }^{3}$ p. 228). However, our own direct participant observation in a large research institution (e.g. Knorr ${ }^{35,36}$ ) suggest that supervisory scientists, rather than feeling "obliged" by their rank to "concede" seniority position to a less established author, often insisted on being placed last in the order of authors because this position would convey their rank to the audience and thus reinforce their authority.
} 
then analyze a series of other variables with respect to productivity and identify those factors which account for most of the variance in the present data. Finally, these factors will be summarized and their relative impact determined for different types of intellectual environment (i.e. disciplines and organizational context) by using the Lisrel technique.

\section{Data and measurement}

The data presented here come from an international comparative study of the organization and-performance of research units done in 6 European countries (Austria, Belgium, Finland, Hungary, Poland and Sweden). In each country, a sample of 150-250 research units ${ }^{\mathrm{a}}$ stratified according to type of organizational setting (academic, cooperative and industrial) ${ }^{b}$ and scientific field ${ }^{\mathfrak{c}}$ has been taken. In total, data from 1222 research units and from 4057 scientists mainly working in the natural and technological sciences were collected by means of 5 different questionnaires. The questions were based on a pretest of 150 research units in 3 countries and addressed to unit heads (personal interview), scientists of the unit (self-administered questionnaires), ${ }^{d}$ the technical and service staff of the unit (self administered questionnaires), and to external evaluators of the work of the unit (personal and self administered). The response rate varied between 70 and $85 \%$

aA "research unit" has been defined for the purpose of this international study as a group of scientists which meets the requirement of having specific scientific-technical responsibilities, a distinct life-span, at least one leader and altogether 3 core members spending at least 8 hours/week in the unit. Furthermore, the group must have had an expected life time of at least one year and the individual scientist, in order to be considered as a core member and as eligible for answering the questionnaire, must have been in the unit for at least 6 months. Individual scientists not belonging to a research unit were excluded from the survey.

b The category "academic settings" comprises, beyond universities, institutes attached to universities and academies of science. The category "cooperative institutes" comprises those research units which belong to institutions wholly or partly serving a branch of industry and/or to government institutions. In the international data set, the academic sector is overrepresented; it comprises 2566 respondents as compared to 744 in cooperative institutes and 657 in industrial enterprizes.

cTerms such as "field" or "discipline" are used here in accordance with the Unesco "International Standard Nomenclature for Fields of Science and Technology"|upon which the sampling procedure was based. The international data include the following fields by number of respondents: Physical Sciences (280); Chemical Sciences (825); Life Sciences (708); Earth and Space Sciences (228); Agricultural Scieıces (331); Medical Sciences (189); Technological Sciences (1176); Social Sciences (258); and others such as Mathematics, Astronomy etc. (62).

dIf a unit comprised more than 3 core members, 3 scientists of the unit were randomly selected as respondents. 
depending on countries and fields of study with no indication of a serious response bias by rank of respondents, field or type of organization. A more comprehensive description of the survey can be found in Andrews. ${ }^{28}$

Following a frequent procedure (e.g. Pelz and Andrews, ${ }^{22}$ Hagstrom, ${ }^{40}$ Gaston $^{16}$ ) we took as our indicator of publication productivity the self-reported number of papers a respondent had published in scientific journals in connection with his work in the research unit during the last 3 years. ' Since they presumably measure the quality rather than the quantity of a scientis's output, citation counts are probably a more reliable measure of productivity. ${ }^{b}$ However, as pointed out by Allison and Stewart (Ref. ${ }^{26}$ p. 599), there is at least one reason to question their validity in studies of accumulative advantage. Citations can also be interpreted to measure the recognition a scientist receives for his work, a dimension which belongs to the set of explanatory concepts with respect to the above hypothesis and hence ought to be excluded from productivity measurement. In general, citation counts have met with a variety of criticisms in recent years (see Chubin and Moitra, ${ }^{41}$ Sullivan et al., ${ }^{42}$ Chubin and Studer). ${ }^{43}$ Finally and most decisively in the present case of an international comparative study, not all European countries included in the survey are adequately or equally well covered by the Science Citation Index. For a more detailed discussion and evaluation of the performance measures used in the present study see Andrews. ${ }^{28}$

In general, academic natural science settings, academic technological science research and industrial settings (technological research) ${ }^{c}$ were choosen as relevant cognitive environments for which all analyses were conducted separately. This decision was based upon a thorough investigation of performance measures in different disciplines and types of organization as reported in Cole, ${ }^{44}$ which showed that performance differs markedly in the above settings whereas no significant gain was made by looking at more narrowly defined environments.

${ }^{\text {a To }}$ check the reliability of the responses, lists of publication and reprints/preprints collected for other purposes from a sample of scientists were matched against the data supplied by respondents, resulting in correlations of $0.85-0.96$. Where the Lisrel technique was used, the number of scientific books published in the same time period was included in the analysis as a second indicator of publication productivity, justified by a sufficiently high correlation between the measures.

As expected, both measures were highly skewed in that only a small number of scientists proved to be highly productive, while most scientist either had not produced at all or reported only a few papers. To reduce skewness, the usual transformations were employed (see Ref.. ${ }^{28}$ ).

${ }^{b}$ For a general review and defense of bibliographic measures see Narin ${ }^{39}$ and Cole and Cole. ${ }^{60}$

${ }^{\text {c }}$ Technological sciences as defined by the Unesco Nomenclature basically comprise all applied branches of natural science disciplines (such as chemical engineering) in addition to inherently technological specialties such as materials technology. 


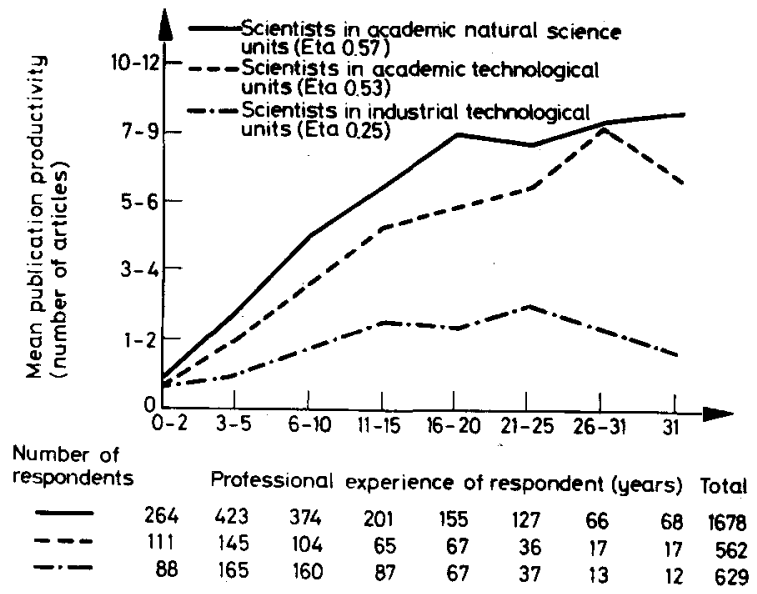

Fig. 1. Mean publication productivity and professional "age" for scientists in academic natural and technological sciences as well as for scientists in industrial units

\section{Age as a proxy for position in the research laboratory}

Earlier work suggested a somewhat curvilinear relationship between a scientist's age and his or her scientific productivity (Lehman, 45-4 ${ }^{4 e l z}$ and Andrews ${ }^{2}$ ). In general, our data support these results: Fig. 1 shows a more or less continuous rise of publication productivity for the first 20-30 years (depending on organizational setting and field) of professional "age", by which we mean the number of years of R\&D experience of a scientist. The latter concept was introduced in addition to chronological age in order to adjust for differential disadvantages of those scientists who started their career later (e.g. because of the war). Both measures turned out to be highly correlated, and the difference between productivity curves is negligeable for the present purpose. ${ }^{a}$

The curvilinear relationship shown is seemingly consistent with an interpretation often found in connection with the sacred spark hypothesis. Accordingly, the increase of productivity with age is accounted for by the increasing competence of highly gifted and motivated scientists, while stagnation and decline after a period of rising achievement is explained by the assumption that the more productive

\footnotetext{
${ }^{a}$ The curve for chronological age can be found in Knorr et al. ${ }^{4}$ The Pearson'r between chronological age and professional experience for academic natural scientists and for technological scientists's in academic and in industrial environments is $0.85,0.83$ and 0.76 , in the above order.
} 


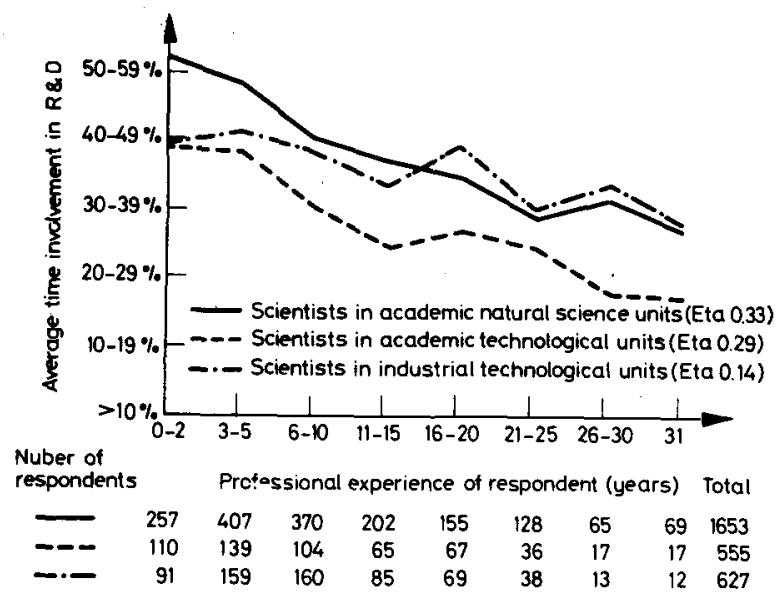

Fig. 2. Mean percentage of time in research and professional experience for scientists in academic natural and technological science and for industrial units

scientists are drawn off into teaching, administration and other work not productive of scientific output. Interpretations such as the latter may be influenced by results on inter-institutional and inter-sectoral mobility (cf. Hargens, ${ }^{24}$. Mullins, ${ }^{61}$ Zuckerman, ${ }^{62}$ Zuckerman and Merton ${ }^{18}$ ) as well as by reliance on summary measures. For example, our data show a negative correlation between age and \% time spent in research, and positive correlations with time spent on administration and with the number of years a scientist had been head of the unit. ${ }^{a}$ However, closer examination reveals a more or less steady decrease of the time spent in research and an equally steady increase of administrative tasks from the very beginning of a professional career almost to the end of it, while publication productivity was shown to be nevertheless rising sharply in academic settings and moderately in industrial settings for at least the first 20 years of a career (cf. Fig. 1). ${ }^{b}$ As an example, Fig. 2 shows the decreasing involvement in research activities with age which holds in all 3 intellectual environments studied in this paper.

'The Pearson'rs between age and years as head of unit, $\%$ research and $\%$ administration are $0.47,-0.36$ and 0.44 in academic natural science settings; $0.36,-0.34$ and 0.37 in academic technological sciences; and $0.39,-0.14$ and 0.26 for technological scientists in industry.

"Since the possibility of an "ecological fallacy" is not ruled out out by graphs such as the following, let me cite the $E t a^{2}$ coefficients for the relationship between time spent in research and productivity which turn out to be near zero as they should be $(0.04$ in academic natural science and industrial units) and which will be explored in more detail in the next paragraph. 
Table 1

Pearson'rs between age/experience and publication productivity for different subgroups of academic scientists

\begin{tabular}{l|c|c}
\hline \multirow{2}{*}{ Subgroups of academic scientists } & \multicolumn{2}{|c}{ Person'r of productivity with } \\
\cline { 2 - 3 } & $\begin{array}{c}\text { chronological } \\
\text { age }\end{array}$ & $\begin{array}{c}\text { professional } \\
\text { experience }\end{array}$ \\
\hline Unit heads & & \\
$\quad$ natural scientists & 0.05 & 0.13 \\
technological scientists & 0.00 & 0.13 \\
Unit members & & \\
natural scientists & $0.34^{* *}$ & $0.43^{* *}$ \\
technological scientists & $0.32^{* *}$ & $0.44^{* *}$ \\
Academic natural scientists (total) & $0.46^{* *}$ & $0.51^{* *}$ \\
Academic technological scientists & $0.43^{* *}$ & $0.50^{* *}$ \\
& &
\end{tabular}

The fact that scientists are drawn off from research and drawn into administrative and other tasks from the very beginning of their career suggests that age might be considered as a kind of proxy for the degree to which scientists move into various kinds of informal and formal supervisory positions. ${ }^{\text {a }}$ A simple check of such an assumption was done by asking whether there is any significant direct effect of age and professional experience on productivity over and above the effect which runs through the position a scientist attains in the research unit. If there is such a direct effect it should mean that age stands for rising technical knowledge and competence which accounts for increasing productivity more or less independent of the position a scientist holds and the task structure and resources it provides.

The correlations presented in Table 1 between chronological age/professional experience and productivity for unit heads on the one hand and for staff scientists (which include scientists of various positions below unit heads and non-supervisory researchers) on the other hand underlined the primary importance of position as opposed to age: When position was controlled for, the correlation between age or experience and productivity decreased substantially, while remaining significant for staff scientists (position not controlled for).

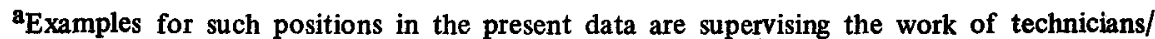
students, directing projects, and finally becoming head of the unit (compare Cotgrove and $B o x^{49}$ ). 


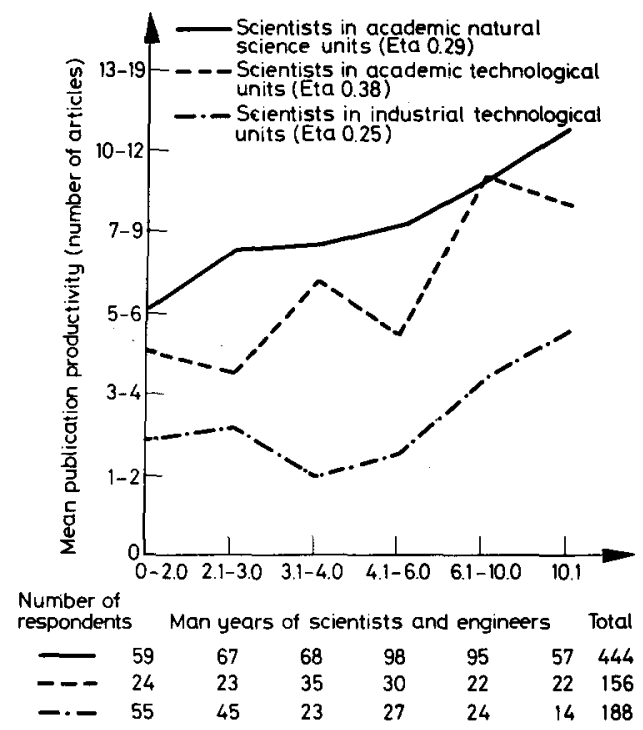

Fig. 3. Mean publication productivity of supervisory scientists for different manpower resources of scientists and engineers at their disposal in academic natural and technological science units and industrial settings

Another more indirect check of the theoretical priority attributed to position for which age stands as a proxy in the present analysis can be done by pointing to the following relationship: if position as opposed to age is to explain publication differentials, then there should be a positive relationship between supervisory scientists' access to manpower resources ${ }^{\mathbf{a}}$ and their productivity, for the simple reason that the number of scientists and supportive staff supervised should act as a multiplying factor as far as the supervisors' quantity of output is concerned. If, however, it was age or professional experience and the presumed rise in personal scientific competence to which increasing numbers of publications per unit of time must be attributed, then there should be no such correlation between supervisors' manpower resources and their productivity.

As can be seen from Fig. 3, there is an almost linear increase of a supervisory scientist's publications (in natural sciences), a two-peaked increase (in technological sciences) with rising resources in highly qualified manpower, and a somewhat less

aManpower resources in both cases are measured in terms of the average number of man years of (a) scientists and engineers (Fig. 3), and (b) technical and supportive staff (Fig. 4) in the unit supervised by the scientists during the last three years. 


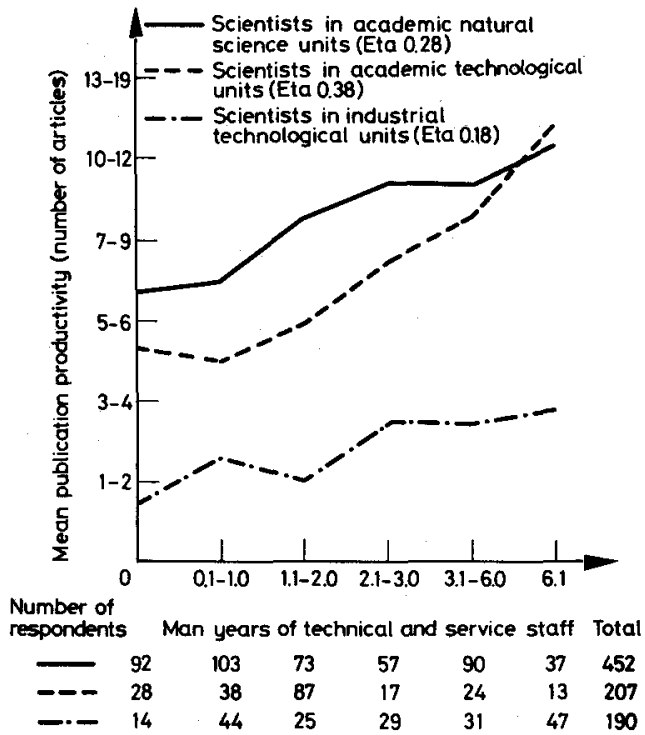

Fig. 4. Mean publication productivity of supervisory scientists for different manpower resources of technical and service staff at their disposal in academic natural and technological science units and in industrial settings

pronounced relationship in industrial settings. Similarly, both fields and both kinds of institutions show a more or less continuous growth of productivity curves with increasing technical and service staff supervised by the scientist (Fig. 4). Since availability of and access to (scientific and technical) manpower resources depend on the position a scientist holds in the laboratory, we might conclude that the existence of the above significant positive relationship supports our general thesis.

\section{Professional position, task structure and productivity}

If age is acting as a proxy for position with a view to productivity in the present data set then age should also be related to certain characteristics of the task structure associated with supervisory positions. We have already shown that the amount of time in research decreases with age from the very beginning of a career, whereas involvements in administrative tasks increase steadily. Since productivity at the same time rises continuously, we might suspect that scientists in general do not profit much in terms of their written productivity from sheer time spent in research. Since this seemed somewhat counterintuitive, productivity curves were plotted for 


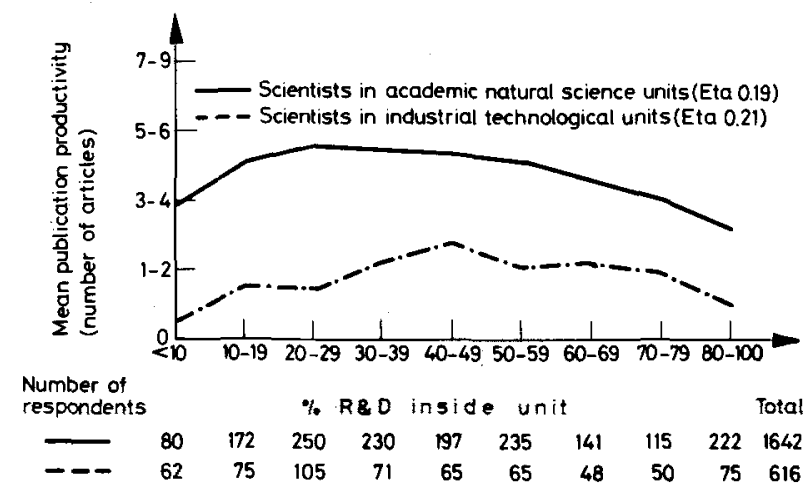

Fig. 5. Mean publication productivity for different time involvements in research with scientists in academic natural sciences and in industrial technological science units

different time involvements, controlling as usual for academic field and type of institution. Fig. 5 shows the result for scientists in academic natural science settings and for industrial laboratories involved with technological research. In both cases, the shape of the curve is slightly curvilinear (compare Pelz and Andrews, ${ }^{22}$ ): time involvements lower than $10 \%$ and around $80 \%$ or more do not contribute to achievements. In addition, there is a slight negative effect of more than $1 / 3$ of time spent in research on productivity in academic intellectual environments and a peaking at a somewhat greater time involvement (between 40 and 50\%) in industrial settings. ${ }^{a}$

In sum total, however, relationships do not look impressive, as indicated by Eta ${ }^{2}$ coefficients of 0.04 in both cases. In order to more specifically address the question of supervisory task structure and its relation to productivity we controlled for a scientist's position in the unit, assuming that time spent on research might play a more pronounced role in the case of the researchers of the unit as compared to units heads (in academic settings often university professors).

Fig. 6 shows the resulting productivity curves for both kinds of scientists in academic natural science units. Somewhat unexpectedly, relationships were particularly weak for researchers: except for the well known negative effect of ex-

aIt might be argued that scientists should find it difficult to give an accurate estimate of the time they spend on various tasks. However, for the present purpose precision with respect to the absolute quantity of percentages is unnecessary. In order to match the Likert scales used elsewhere in the survey the self reported time estimates need not be interpreted to achieve more than an ordering of respondents into five categories which range from almost no research to almost nothing but research. 


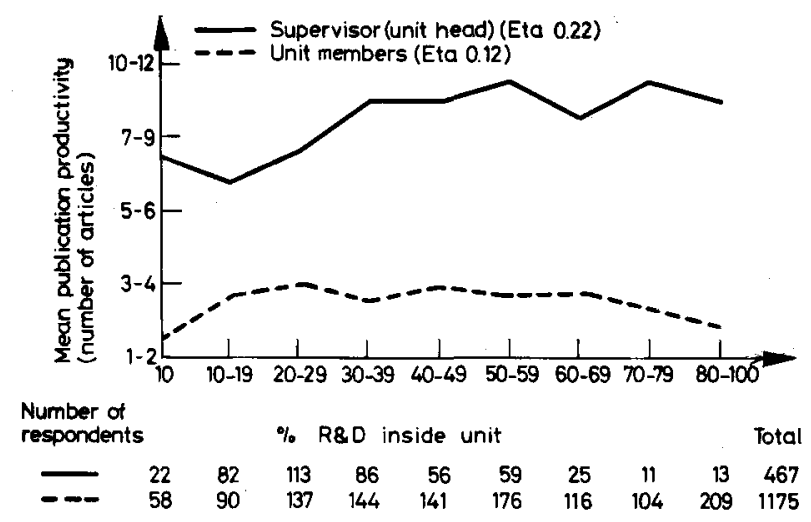

Fig. 6. Mean publication productivity for different time involvements in research for unit heads and unit members in academic natural science settings

tremely little or extremely much research, productivity seemed to be more or less independent of how much research a scientist was actually doing. If it pays for somebody to be more involved with research, then it is the supervisor in the highest position or head of unit who reaches a higher level of productivity by spending at least $30 \%$ of his time on research activities.

If sheer time in research seemingly does not contribute significantly to the publication productivity of a scientist then it should be the changing nature of involvement in research associated with attainment of supervisory positions which makes for a difference. ${ }^{a}$ Being involved in many projects with a relatively low amount of time mainly at an early (research conceptualization) and late stage (report and paper writing) clearly offers better opportunities for author- or coauthorship than devoting a large amount of time to actually do all the tedious work of one research task. Consequently, if the negative relationship between age or experience and time in research and the lack of a significant correlation between time in research and productivity (except for extreme time involvements) can be supplemented by a positive relationship between age/experience and the degree to which the scientist is charged with goal setting rather than goal executing functions (positively related to productivity), this should support our argument that it is the differential advantages associated with supervisory positions which account for much of the productivity differences in research organizations.

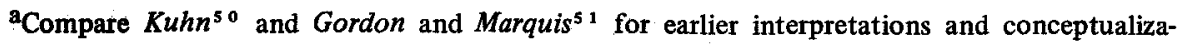
tions of the "nature of involvement". 
Table 2

Pearson'rs between various dimensions of the research task structure of a scientist, of publication productivity and

of professional experience in academic settings

\begin{tabular}{c|c|c|c|c}
\hline \multirow{2}{*}{$\begin{array}{c}\text { Dimensions } \\
\text { of task structure }\end{array}$} & \multicolumn{2}{|c|}{$\begin{array}{c}\text { Academic natural } \\
\text { scientists }\end{array}$} & $\begin{array}{c}\text { Academic technological } \\
\text { scientists }\end{array}$ \\
\cline { 2 - 5 } & $\begin{array}{c}\text { years of prof. } \\
\text { experience }\end{array}$ & $\begin{array}{c}\text { publication } \\
\text { productivity }\end{array}$ & $\begin{array}{c}\text { years of prof. } \\
\text { experience }\end{array}$ & $\begin{array}{c}\text { publication } \\
\text { productivity }\end{array}$ \\
\hline $\begin{array}{c}\text { Diversity of functions } \\
\text { Degree of legislative involve } \\
\text { ment in research }\end{array}$ & $0.34^{* *}$ & $0.28 * *$ & $0.32^{* *}$ & $0.24 * *$ \\
$\begin{array}{c}\text { Number of total projects in- } \\
\text { volved in research }\end{array}$ & $0.40^{* *}$ & $0.42^{* *}$ & $0.38^{* *}$ & $0.34^{* *}$ \\
\end{tabular}

* *Significance $\leqslant 0.001$.

To check our argument the following 3 dimensions have been chosen to represent - to various degrees - a goal setting task structure:

First, the diversity of functions of a scientist, an index based on a simple count of every incidence of a greater than $0 \%$ time involvement of the scientist in (a) research, (b) teaching, (c) administration, and (d) other scientific activities (like

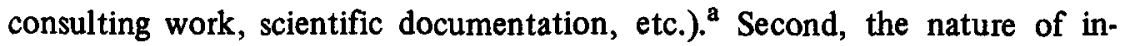
volvement in $R \& D$ as conceived of the degree to which she was involved in goal setting research functions which set the stage for execution by others (like "perception and identification of an area of interest" for the unit) as opposed to genuinely executing tasks (like "collection and production of data" or "literature review"). The third concept referred to the total number of projects a scientist was involved in, as an indicator of the ability to attract resources in connection

The range of the index accordingly varies from 1-4; the index is based on a general question as to how much of the total work time of the scientist this year was devoted to the above categories, additionally including "routine and control analyses", "design and engineering studies" and "other professional functions" under category (d) above.

bIndicators used to measure the volume of goal setting functions are the following: degree of involvement in "perception and identification of an area of interest", in "problem precision: conceptualization, formulation, analysis", in "time-table, administration, organization and economic considerations" and in "formulation and statement of hypothesis"; all items were measured on 5-point Likert scales. 
with the work in the unit. All three dimensions were thought to mirror the position a scientist held in the unit in that the higher she moved in the hierarchy of the research laboratory the more she would be confronted with a variety of scientific and non-scientific functions in addition to research, the more the nature of involvement into research should change towards goal setting rather than executing activities, and the more she should be able to attract project money and consequently be involved as a supervisor or just formally in more projects within and outside the unit than at the beginning of a career. As can be seen from Table 2 representing correlation coefficients between the above dimensions of supervisory task structure and position (as approximated by professional "age") or productivity respectively, the data substantiate these expectations..

\section{A professional position model of publication productivity}

We have shown so far that age and professional experience are acting as a kind of proxy for the degree to which a scientist holds a supervisory position ${ }^{\mathrm{a}}$ and that the manpower resources and task structure associated with this position relate positively to a scientist's publication productivity. As a final check on our general thesis we now present a path analytic model of the presumed structure of relationships as implied so far, ignoring for a moment manpower resources which were only measured for the subgroup of unit heads. The fit of the path analytic model set up to represent this structure has been tested with the help of the Lisrel technique (cf. Jöreskog and van Thillo, ${ }^{52}$ Jöreskog $^{53}$ ).

Lisrel is a computer program for estimating general linear structural equation models with the special advantage of allowing for unmeasured hypothetical constructs or latent variables measured by several indicators each. In relation with this, the method allows for a differentiation between errors in equations (disturbances) indicating the amount of variance explained and errors in the observed variables (measurement error), yielding estimations for both. ${ }^{\mathrm{b}}$

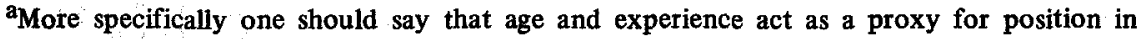
relation to publication productivity since there seems to be no direct effect of age over and above what is explained by a scientist supervisory position.

bIn the case of highly skewed measures such as publication counts linearity assumptions of Lisrel were met by employing the necessary transformations, as pointed out previously. A final test of the linearity of bivariate relationships showed no significant non-linearity in the data (see Wallers 4 ). 


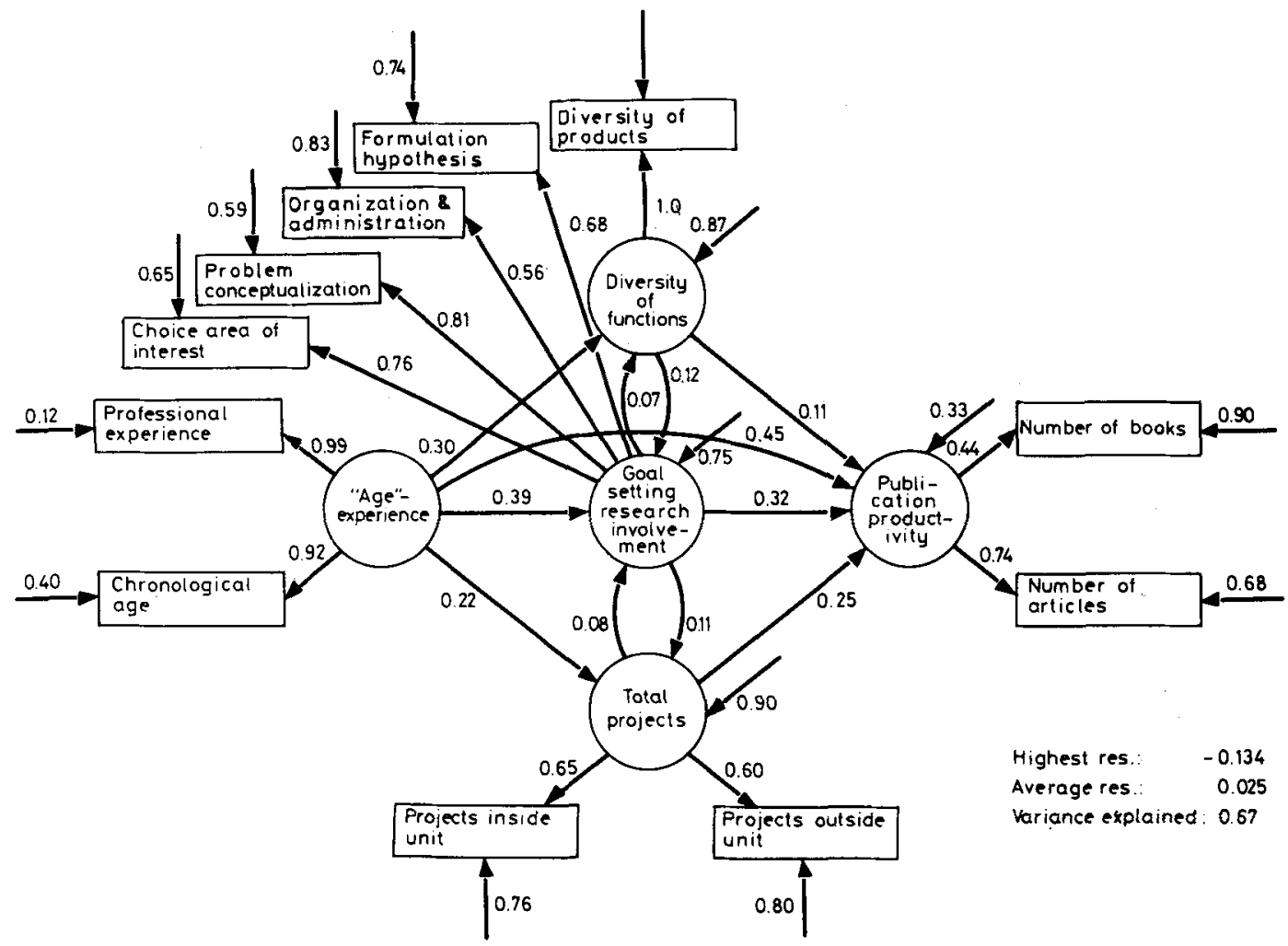

Fig. 7. Lisrel model of individual publication productivity as a professional position effect for scientists in academic natural science units

All parameters reported in the models pertain to standardized variables. Linkages between latent dimensions (circles) represent true relationships ${ }^{a}{ }^{1}$ and are reported as path coefficients, those between observed (rectangles) and unobserved dimensions represent the construct validity of the measures reported as regression coefficients $\left(J_{o ̈ r e s k o g}{ }^{3}\right.$ ). Arrows pointing to observed ${ }^{b}$ variables indicate the

aTo ensure the identifiability of the model parameters representing symmetric linkages between the unobserved dimensions of functions and tasks performend by the scientist were constrained to be "equal", which means that the Lisrel algorithm allows only for minor variations in the size of the respective coefficients.

bIn case of only one observed indicator for a latent dimension (diversity of functions) the linkage between the two was fixed at 1.0 with a corresponding measurement error of 0.0 in the observed indicator. 


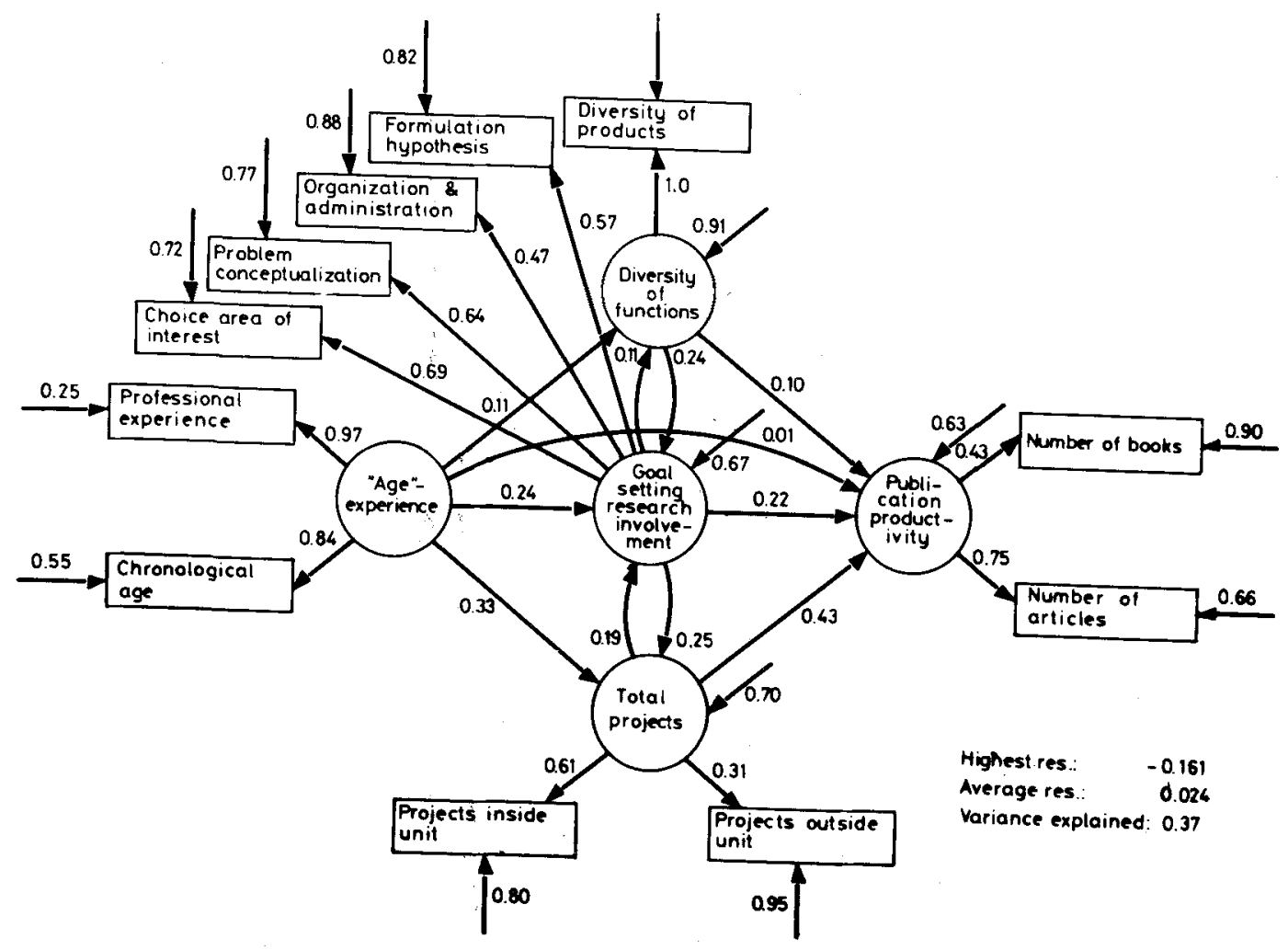

Fig. 8. Lisrel model of individual publication productivity as a professional position effect for scientists in industrial technological science units

amount of measurement error, those pointing to latent dimensions indicate disturbances or residuals.

As in previous analyses, we chose scientists in academic natural science and technological science units as well as scientists in industrial units as relevant subgroups for replacing the model. Results for academic natural sciences are shown in Fig. 7, results for technological sciences in industry are presented in Fig. 8. The model for academic technological science settings is not included since results are similar to those for natural sciences, with an even higher amount of variance explained.

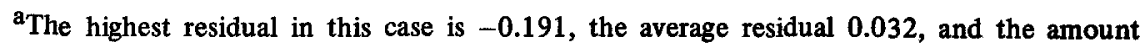
of variance explained is $81 \%$. 
The ability of Lisrel to reproduce the input correlations among observed variables was generally good: the mean deviation of the estimated correlations from the observed correlations in the model of Fig. 7 is 0.025 , in Fig. 80.024 ; highest discrepancies were -0.134 and -0.161 respectively. What the model substantiates basically is that a scientist's age as a proxy for the degree to which she holds a supervisory position is related to task structure in the research laboratory and this in turn is related to his or her publication productivity. Since the method allows for multiple indicators (as shown by rectangles in Figs 7 and 8) of one concept (as shown by circles), "age" is measured by both, chronological age and professional experience.

Supervisory task structure as previously is represented by three dimensions: the diversity of functions, the volume of goal setting research functions and the number of projects a scientist is involved in. Positive relationships between these dimensions and the voluntary overtime scientists devote to work or to his attachement to the research unit can be shown ${ }^{\mathrm{a}}$ but were left out of the model, since they contribute practically nil to explaining publication productivity when other concepts are controlled for. When screening the data with a view to detecting potential other organizational effects upon individual publication productivity, no further variables imposed themselves as being significantly related to individual scientists' output in academic settings. It is important to note that the five-variable pattern of relationship which identifies supervisory position as the major explanatory concept accounting for intraorganizational productivity differences seemingly dominates over all other relationships between organizational variables and publication productivity which might be hypothesized. ${ }^{b}$

\section{Technological scientists in industrial research units}

From an inspection to Figs 7 and 8 it can be seen that both models in general show good fit as indicated by highest and average residuals, yet the amount of variance explained in individual productivity varies greatly between both types of institutions involved: there is a decrease of $30 \%$ between the variance explained

aTo give an example, Pearson'rs between the age of a scientist and attachement to the unit are 0.36 for academic natural scientists and 0.24 for scientists in industry.

b The variables and their interrelationship as used in the Lisrel model have also been explored with the help of the Goodman approach..$^{5-57}$ The resulting model showed no significant interaction between the variables; furthermore, the model showed an excellent fit in accordance with what we would expected from the Lisrel results (see Waller ${ }^{54}$ ). 


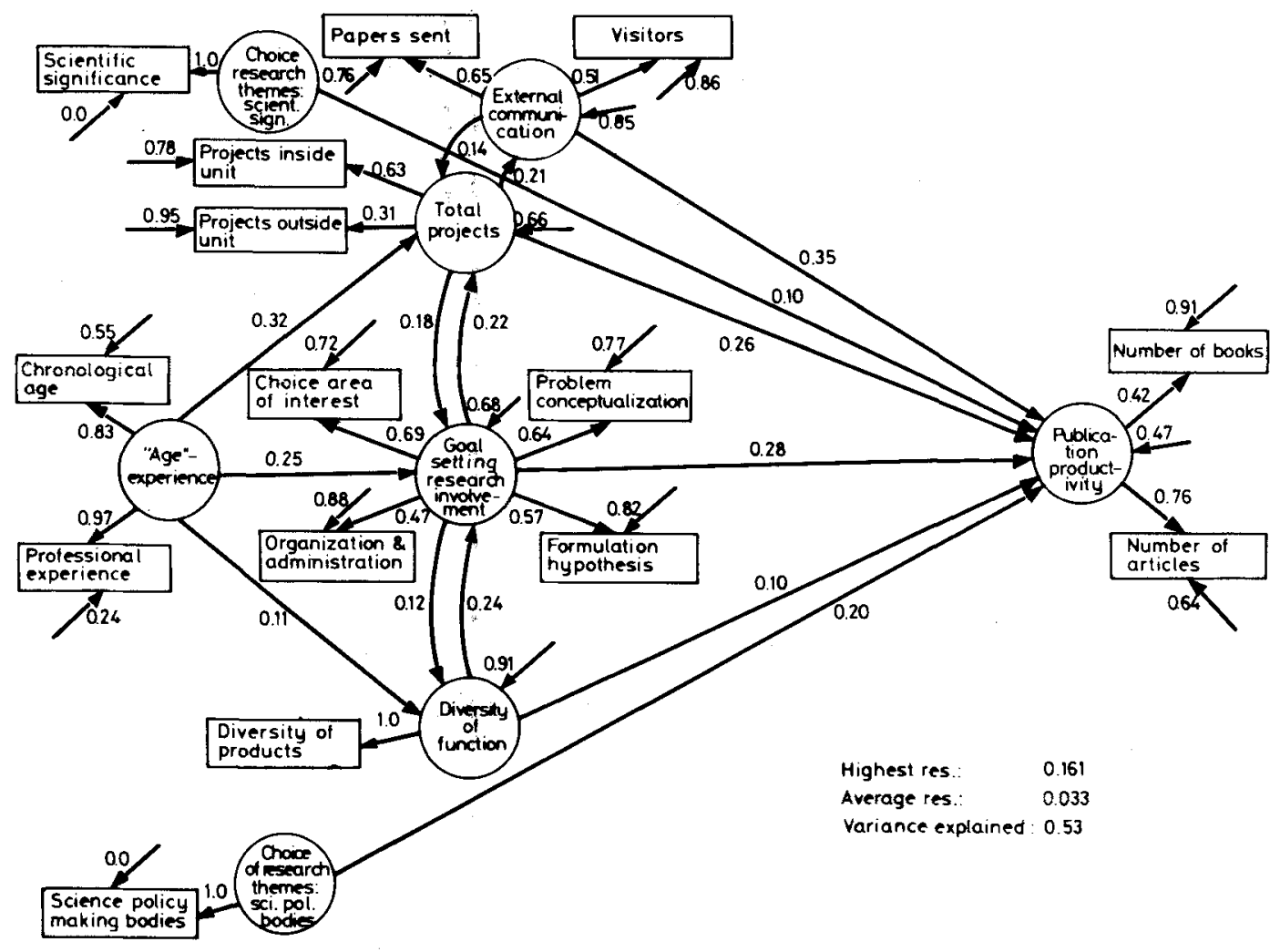

Fig. 9. Lisrel model of individual publication productivity including choice of research themes for technological scientists in industry

with the model for scientists in academic natural science settings (67\%) and for scientists in industrial firms $(37 \%)$. $^{\text {a }}$

The lower amount of variance explained by the professional position model of publication productivity in industrial research points to potential other factors specific to this setting which should be taken into account. Fig. 9 presents a model which includes two principal other sources of explanation, one referring to

aParameter estimates for both models differ most markedly as far as the importance of the total number of projects is concerned - which seems more pronounced in the technological sciences than in the natural sciences - and in relation to the direct linkage between age and publication productivity which practically disappears in industrial research units. 
what influences - and to which degree - the choice of the research theme of an industrial laboratory, the other referring to the degree of external communication ${ }^{\mathrm{a}}$ the unit maintains.

The choice of the research theme can be taken to approximate the cognitive content of the respective technological research (Whitley ${ }^{32-34}$ ). As measured here it subdivides into 2 different factors relevant for enhancing productivity through making an impact on the research topic: not surprising, it is the degree to which scientific significance is taken into account when the research tasks of a laboratory are being determined which influences - directly and indirectly through promoting the external scientific communication of the unit - the probability of an individual researcher publishing his or her results. Second, it is the degree to which science policy making bodies determine the choice of research tasks (as in socialized industry) which is also related positively to publication activities. Whereas the first factor seemingly points to an industrial research unit's orientation towards basic research which is linked to external communication and to more emphasis on publications, the second factor could imply a certain policy of legitimizing public (government) money spent on research by pressure towards publishing all the results obtained. $^{\mathbf{b}}$

Reproduction of observed correlations by parameters produced by the Lisrel program was goot again: the average discrepancy between observed and fitted covariances is 0.033 , the highest discrepancy is -0.161 . The model now accounts for somewhat more than half of the variance in individual publication productivity in setting (53\%), with about $15 \%$ of gain by adding the above variables.

\footnotetext{
Two indicators have been chosen as measures of unit-external scientific communication: the number of visiting scientists from the country who had visited the unit during the past year and the number of publications of the unit sent to other individuals or organizations in the field. Several other indicators could also be used here; e.g. the number of scientists from abroad or the number of publications received by the unit (cf. Knorr et al. ${ }^{4}$ ). It must be noted, however, that the number of publications sent to other groups might be a result rather than an origin of publication productivity; the same holds - to a less obvious degree for all indicators of external contacts. This points to the hypothetical character of the causal links specified, which should be kept in mind when interpreting the models.

bSee Weingart $^{39}$ and Küppers et al. ${ }^{58}$ for detailed explorations of the social and political context with regard to the technological sciences.
} 


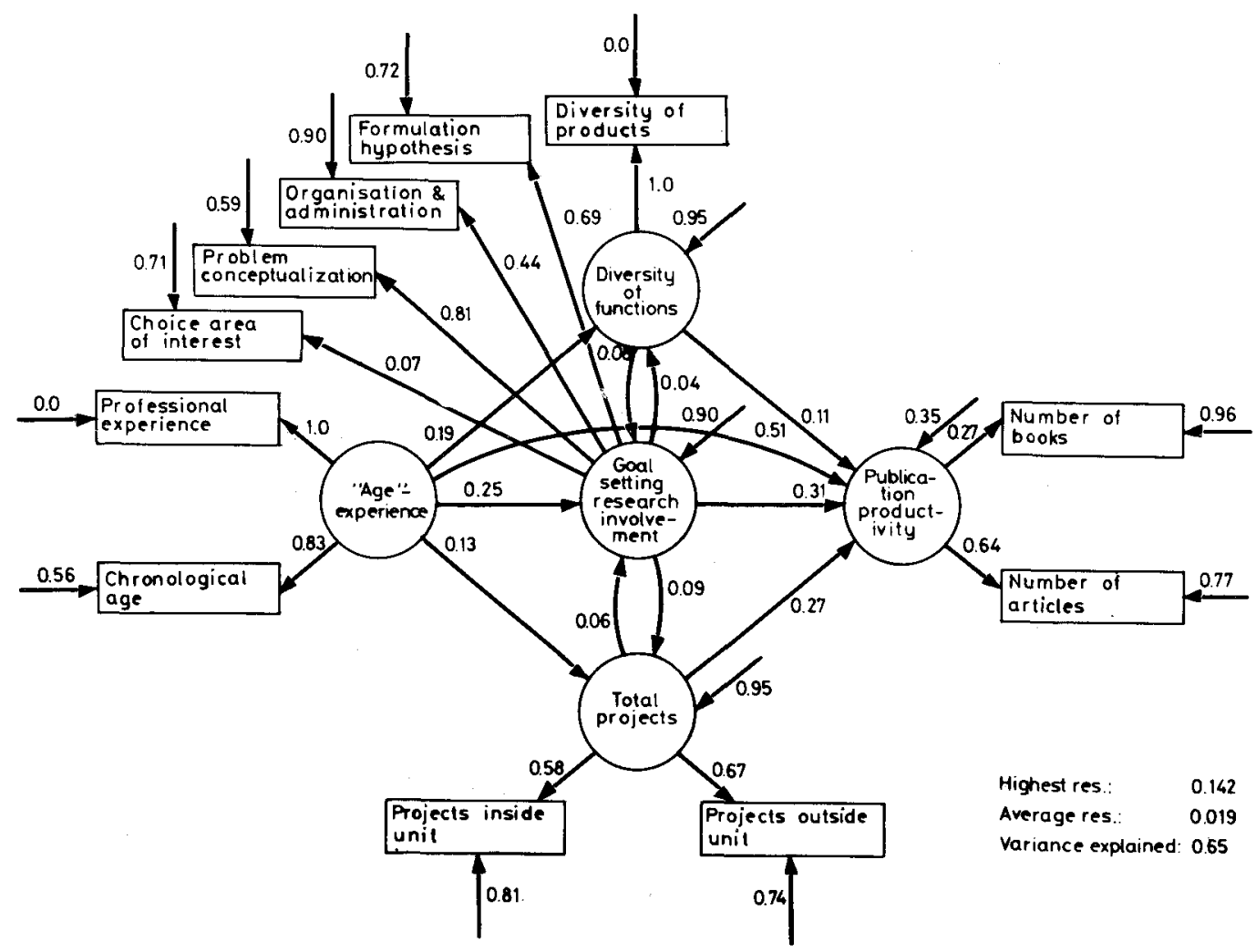

Fig. 10. Lisrel model of individual publication productivity as a professional position effect for academic natural sciences (excluding unit heads)

\section{Control for a scientist's position}

As can be seen from an inspection of the model presented in Fig. 7 there remains a relatively high direct effect of age and professional experience on publication productivity in academic settings. ${ }^{2}$ We have already shown that the relationship between age/experience and productivity tends to disappear when a scientist's supervisory position is controlled for (see Table 1). In order to check the validity of

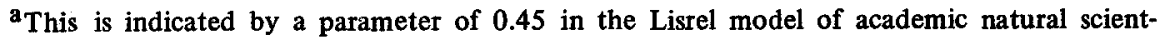
ists (see Fig. 7) and by a parameter of 0.36 for academic technological scientists (model not included). It is worthwhile noting that this direct effect disappears in industrial settings and hence the linkage has been eliminated in the final model (see Fig. 8 and Fig. 9). 


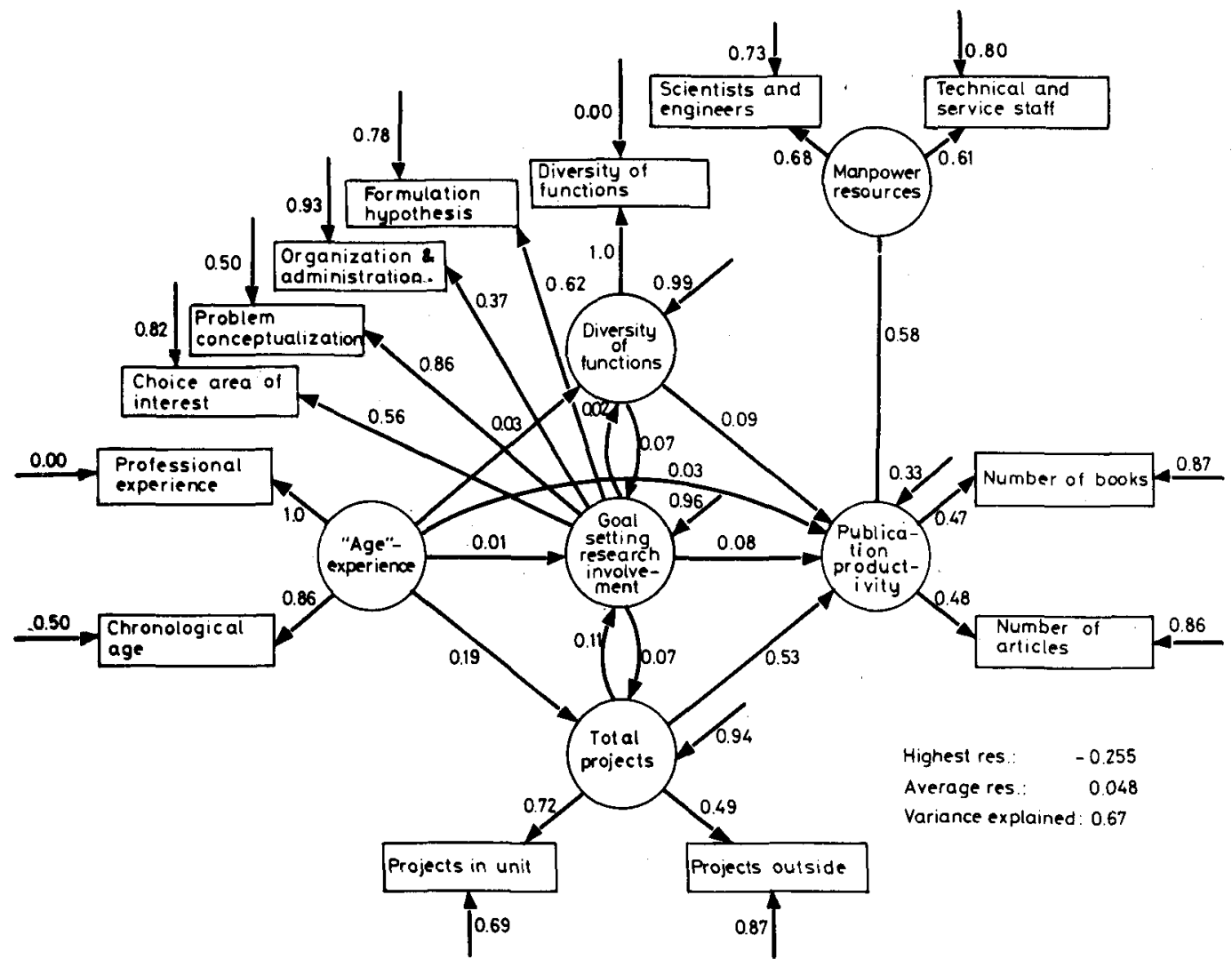

Fig. 11. Lisrel model of individual publication productivity for supervisory scientists (unit heads) in academic natural science settings

our previous argument in the case of multivariate relationships we are now confronted with, we replicated the professional position model of individual publication productivity in academic natural science settings for supervisory scientists (unit heads) and unit members separately. In accordance with what we have said so far the model would be expected to replicate nicely for unit members (since this subgroup includes various kinds of supervisory position below unit heads), but should, being a professional position model, change significantly when unit heads are looked at exclusively. Figs 10 and 11 substantiate these expectations: In the case of staff scientists (Fig. 10) of a unit the model maintains its significance, with only slight changes in the parameters linking concepts, and an explained variance in productivity of $65 \%$ (as compared to an original 67\%). In the case of unit heads (Fig. 11) the model was replicated in- 
cluding the variable quantity of manpower resources at the heads' disposal (and not measured for unit members). The latter variable yields the highest path coefficient in the resulting model, followed by the variable "number of projects" the supervisor is involved in and suggesting that once a supervisory position is attained manpower resources and project tasks account for most of the variance in further productivity differences. In accordance with this, the direct relationship between age/experience and productivity is reduced to 0.03 (from 0.45 in the global model!), clearly indicating that there is no remaining effect of age once position and what it stands for are taken into account.

\section{Conclusion}

According to the preceding analysis, individual productivity when analyzed in terms of organizational variables is mainly accounted for by the professional position the scientist holds in the scientific hierarchy of his organization. The interpretation advanced here has attributed differences in publication rates to the operation of the stratification system inside organizations. Advancement on the formal or informal hierarchy is associated with differential access to resources and with differences in functions and research activities, which in turn leads to a higher probability of author- and coauthorship for the respective scientist. This hypothesis suggests that the professional position of a scientist within specific organizational settings significantly affects the quantity of publications a scientist can turn out irrespective of his personal innovativeness and research talent.

Some of the limitations of the preceding analysis can be made apparent by pointing to the fact that the present data do not allow for a check of a scientist's original production capacities, thus leaving open the question whether and what individual talent contributes to a scientist's first advancement in the professional hierarchy. Our data do, however, allow to call into question the argument that a scientist's productivity suffers as she takes on supervisory duties which involve higher percentages of non-research tasks and hence keep him or her from pursueing research work. Except for the more rare case when a scientist leaves the professional hierarchy altoghether she seems not to be drawn off, but rather to be drawn into publication productivity by advancement in the hierarchy whatever the original production capacities may have been.

${ }^{\text {a }}$ Meltzer $^{7}$ showed a negative association between age at first publication and career productivity and points to the general proposition that the best predictor of an activity is a specimen of past performance in the activity. See also Clemente. ${ }^{10}$ 
In connection with this the results obtained can be used to shed light on the meaning of "productivity" as measured by publication counts and on some of the earlier findings relating to it. For example, results which were taken to suggest that higher rank scientists are more productive in larger groups (Blume and Sinclair ${ }^{20,21}$ ) can be reinterpreted in the light of the present findings as showing the advantages higher rank scientists gain from staff size. In the case of unit heads in academic settings (mostly university professors), these advantages appear to operate independently of the kind of academic functions and research activities unit heads are involved in, as suggested by a significantly reduced contribution of the respective variables (see Fig. 11). However, the model does suggest that these advantages will have to be associated more with the high position scientists' ability to mobilize project and manpower resources - that is with specific professional management functions - than with authorship privileges deriving from the office per se. Thus, if our data do not favor explanations of productivity differences in terms of individual research talent independent of prefessional position, they also do not support explanations which simply reverse the argument to account for productivity as the "unmerited" reflex of authorship rights associated with icertain positions. Our data do, however suggest that we may have to look much more closely at the processes of research production which underly publication productivity, and at the channels, mechanisms and means of production connected with different professional positions in the hierarchy of specific organizational environments.

We are grateful to Frank Andrews, Stewart Blume, Gerald Cole, Diana Crane and Eric van Hove for their valuable comments and critical remarks on earlier versions of this paper. We thank G. Aichholzer, R. Kofler, R. Matuschek, W. Raidl and G. Waller for their help in preparing the analysis and the manuscript.

\section{References}

1. A. Y. LOTKA, The Frequency Distribution of Scientific Productivity, Journal of the Washington Academy of Sciences, 16 (1926) 317-323.

2. D. de SOLLA PRICE, Little Science, Big Science, Columbia University Press, New York, 1963.

3. R. K. MERTON, The Matthew Effect in Science, Science, 59 (1968) 56-63.

4. L. MELTZER, Scientific Productivity in Organizational Settings, Journal of Social Issues, 12 (1956) 32-40.

5. L. MELTZER, J. SALTER, Organizational Structure and the Performance and Job Satisfaction of Physiologists, American Sociological Review, 27 No, 3 (1962) 351-362. 
6. K. CLARK, America's Psychologists, American Psychological Association, Washington, D. C. 1957.

7. B. M. MELTZER, The Productivity of Social Scientists, American Journal of Sociology, 55 (1949) 25-29.

8. L. J. AXELSON, Differences in Productivity of Doctorates in Sociology, Journal of Educational Sociology, 33 (1959) 49-55.

9. N. BABCHUK, A. BATES, Professor or Produce: The Two Faces of Academic Man, Social Forces, 40 (1962) 341-344.

10. F. CLEMENTE, Early Career Determinants of Research Productivity, American Journal of Sociology, 79 No. 2. (1974) 409-419.

11. K. D. KNORR, M. HALLER, W. ZEHETNER, G. ZILIAN, Erkenntnis- und Verwertungsbedingungen sozialwissenschaftlicher Forschung, Jugend und Volk Verlag, Vienna, 1980.

12. J. BEN-DAVID, Scientific Productivity and Academic Organization in Nineteenth Century Medicine, American Sociological Review, 25 (1960) 828-843.

13. D. CRANE, Scientists at Major and Minor Universities: A Study of Productivity and Recognition, American Sociological Review, 30 (1965) 699-714.

14. P. THOMASSON, J. STANLEY, Exploratory Study of Productivity and 'Creativity' of Prominent Psychometricians, Unpubl. manuscript, Univ. of Wisconsin, 1966.

15. S. COLE, J. R. COLE, Scientific Output and Recognition. A Study in the Reward System in Science, American Sociological Review, 32 (1967) 377-390.

16. J.C. GASTON, Big Science in Britain: A Sociological Study of the High Energy Physics Community. Ph. D. thesis, Yale University, New Haven, 1969.

17. J. COLE, Patterns of Intellectual Influence in Scientific Research, Sociology of Education, 43 (1970) 377-403.

18. H. A. ZUCKERMAN, R. K. MERTON, Patterns of Evaluation in Science, Institutionalization, Structure and Functions of the Referee System, Minerva, 9 (1971) 66-100.

19. W. O: HAGSTROM, Inputs, Outputs and the Prestige of University Science Departments, Sociology of Education, 44 (1971) 375-397.

20. S. S. BLUME, R. SINCLAIR, Chemists in British Universities: A study of the Reward System in Science, American Sociological Review, 38 (1973) 126-138.

21. S. S. BLUME, R. SINCLAIR, Research Environment and Performance in British University Chemistry, Science Policy Studies, No. 6, HMSO, London, 1973.

22. D. C. PELZ, F. M. ANDREWS, Scientists in Organizations, Productive Climates for Research and Development, Wiley and Sons, New York, 1966; Second, enlarged and revised edition, 1976.

23. L. L. HARGENS, W. O. HAGSTROM, Sponsored and Contest Mobility of American Academic Scientists, Sociology of Education, 40 (1967) 24-38.

24. L. L. HARGENS, Patterns of Mobility of New Ph. D.'s among American Academic Institutions, Sociology of Education, 42 (1969) 18-37.

25. L. L. HARGENS, Patterns of Scientific Research: A Comparative Analysis of Research in Three Scientific Fields, American Sociological Association, Washington, D. C. 1975.

26. P. D. ALLISON, J. A. STEWART, Productivity Differences among Scientists: Evidence for Accumulative Advantage, American Sociological Review, 39 (1974) 596-606.

27. R. MITTERMEIR 2 K. D: KNORR, Scientific Productivity and Accumulative Advantage: A Thesis Reassessed, $R \& D$ Management, (1979), in print.

28. F. ANDREWS (Ed.), Scientific Productivity: The Effectiveness of Research Groups in Six Countries, Cambridge Univ. Press, Unesco, London, Paris, 1979.

29. S. COLE, L. RUBIN, J.R. COLE, Peer Review and the Support of Science, Scientific American, 237 (1977) 34-41. 
30. J.R. COLE, S. COLE, Social Stratification in Science, University of Chicago Press, Chicago, 1973.

31. H. A. ZUCKERMAN, Scientific Elite: Nobel Laureates in the United States, The Free Press, New York, 1977.

32. R. WHITLEY, The Sociology of Scientific Work and the History of Scientific Developments, in: Perspectives in the Sociology of Science, S. BLUME (Ed.), Wiley and Sons, New York, 1977.

33. R. WHITLEY, Changes in the Social and Intellectual Organization of the Sciences, in: The Social Production of Scientific Knowledge. Sociology of the Sciences, Vol. 1, E. MENDELSOHN, P. WEINGART, R. WHITLEY (Eds), D. Reidel Publ. Comp., Dordrecht, Holland, 1977.

34. R. WHITLEY, Types of Science, Organizational Strategies, and Patterns of Work in Research Laboratories in Different Scientific Fields, Social Science Information, 17 (1978) 427-47.

35. K. D. KNORR, Producing and Reproducing Knowledge: Descriptive or Constructive? Social Science Information, 16 (1977) 669--696.

36. K. D. KNORR, Contextuality and Indexicality of Organizational Action: Toward a Transorganizational Theory of Organizations, Social Science Information, 18 (1979) 1085-1109.

37. R. WHITLEY, Black Boxism and the Sociology of Science: a Discussion of the Major Developments in the Field, Sociological Review, 18 (1972) 61-92.

38. R. WHITLEY, Components of Scientific Activities, their Characteristics and Institutionalization in Specialties and Research Areas, in: Determinants and Controls of Scientific Development, K. D. KNORR, H. STRASSER, H. G. ZILIAN (Eds), D. Reidel Publ. Comp., Dordrecht, Holland, 1975.

39. P. WEINGART, Wissensproduktion und soziale Struktur, Suhrkamp, Frankfurt, 1976.

40. W. O. HAGSTROM, Competition and Teamwork in Science. Dep. of Sociology, University of Wisconsin, mimeo, Madison/Wisconsin, 1967.

41. D. E. CHUBIN, S. MOITRA, Content Analysis of References: Adjunct or Alternative to Citation Counting? Social Studies of Science, 5 (1975) 423-41.

42. D. SUllivaN, D. H. WHITE, E. J. BARBONI, Co-Citation Analysis of Science: an Evaluation, Social Studies of Science, 7 (1977) 223-40.

43. D. E. CHUBIN, K. E. STUDER, Network Structures in a Cancer Problem Domain: a Reorientation for Micro Studies in the Sociology of Sciences. Working Paper, Georgia Institute of Technology, 1977.

44. G. COLE, Classifying Research Units by Patterns of Performance and Influence: A Typology of the Round 1 Data, in: Scientific Productivity: The Effectiveness of Research Groups in Six Countries, F. ANDREWS (Ed.), Cambridge University Press, Unesco, London, Paris, 1979.

45. M. C. LEHMANN, Age and Achievement, Princeton University, Press, Princeton, N. J. 1953.

46. M. C. LEHMANN, The Chemists' Most Creative Years, Science, 227 (1958) 1213-1222.

47. M. C. LEHMANN, The Age Decremant in Scientific Creativity, American Psychologist, 15 (1960) $128-134$.

48. K. D. KNORR, R. MITTERMEIR, G. AICHHOLZER, G. WALlER, Individual Publication Productivity as a Social Position Effect in Academic and Industrial Research Units. Research Memorandum 117, Institute for Advanced Studies, Vienna, 1976.

49. S. COTGROVE, S. BOX, Science, Industry and Society, Allen\&Unwin, London, 1970.

50. T: S. KUHN, The Essential Tension: Tradition and Innovation in Scientific Research, in: Scientific Creativity, its Recognition and Development, C. W. TAYLOR, F. BARRON (Eds), Wiley and Sons, New York, 1963.

51. G. GORDON, S. MARQUIS, Freedom, Visibility of Consequences, and Scientific Innovation, American Journal of Sociology, 72 (1966) 195-202. 
52. K. G. JÖRESKOG, M. van THILLO, Lisrel: A General Computer Program for Estimating a Linear Structural Equation System Involving Multiple Indicators of Unmeasured Variables. Unpubl. research bulletin, RB-R-26, Educational Testing Service, Princeton, N. Y: 1972.

53. K. G. JÖRESKOG, Analyzing Psychological Data by Structural Analysis of Covariance Matrices, in: Contemporary Developments in Mathematical Psychology, Vol. II, D. H. KRANTZ, R. D. LUCE, R. C. ATKINSON, P. SUPPE (Eds), W. H. Freeman and Comp., San Francisco, 1974.

54. G. WALIER, Individuelle Produktivität in akademischen Forschungsorganisationen: Eine Goodman Analyse. Institute for Advanced Studies, Vienna, 1976.

55. L. A. GOODMAN, A Modified Multiple Regression Approach to the Analysis of Dichotomous Variables, American Sociological Review, 37 (1972) 28-46.

56. L. A. GOODMAN, A General Model for the Analysis of Surveys, American Journal of Sociology, 77 (1972) 1035-1086.

57. L. A. GOODMAN, Causal Analysis of Data from Panel Studies and other Kinds of Surveys, American Journal of Sociology, 78 (1973) 1135-91.

58. G. KUPPERS, P. LUNDGREEN, P. WEINGART, Umweltforschung, die gesteuerte Wissenschafi? Frankfurt, Suhrkamp, 1976.

59. F. NARIN, Evaluative Bibliometrics: The Use of Publication and Citation Analysis in the Evaluation of Scientific Activities, Computer Horizons Inc., Cherry Hill, N. J., 1977.

60. S. COLE, J. R. COLE, Measuring the Qualitiy of Sociological Research: Problems in the Use of the Science Citation Index, American Sociologist, 6 (1971) 23-29.

61. N.C. MULLINS, A Sociological Theory of Scientific Revolution, in: Determinants and Controls of Scientific Development, K. KNORR, H. STRASSER, H. G. ZILIAN (Eds), D. Reidel Publ. Comp., Dordrecht. Holland, 1975.

62. H. A. ZUCKERMAN, Stratification in American Science, Sociological Inquiry, 40 (1970) 235-57. 